Volume 10, Issue 6, November-December 2019, pp. 198-213, Article ID: IJM_10_06_020

Available online at http://iaeme.com/Home/issue/IJM?Volume $=10 \&$ Issue $=6$

Journal Impact Factor (2019): 9.6780 (Calculated by GISI) www.jifactor.com

ISSN Print: 0976-6502 and ISSN Online: 0976-6510

C IAEME Publication

\title{
HEDONIC AND UTILITARIAN ORIENTATION TOWARDS THE PURCHASE INTENTION OF LAPTOP; THE MEDIATING EFFECT OF INFORMATION QUALITY. AN EMPIRICAL STUDY OF GHANA
}

\author{
Mei Qiang \\ School of Management, Department of Marketing, Jiangsu University, 301 Xuefu Road, \\ Jingkou District, Zhenjiang, Jiangsu, P.R. China. \\ Gyamfi-Yeboah Kwabena
}

School of Management, Department of Marketing, Jiangsu University, 301 Xuefu Road, Jingkou District, Zhenjiang, Jiangsu, P.R. China.

\section{Li Wenyuan}

School of Management, Department of Marketing, Jiangsu University, 301 Xuefu Road, Jingkou District, Zhenjiang, Jiangsu, P.R. China

\section{Sikander Ali Qalati}

School of Management, Department of Marketing, Jiangsu University, 301 Xuefu Road, Jingkou District, Zhenjiang, Jiangsu, P.R. China.

Daria Erusalkina

School of Finance, Department of Finance, Jiangsu University, 301 Xuefu Road, Jingkou District, Zhenjiang, Jiangsu, P.R. China.

\begin{abstract}
In our diurnal cycles, a purchase is performed all the time and at this instant, we are always forced to reflect for a second to choose between two main product types being utilitarian and hedonic. Utilitarian products being practical, functional, and instrumental to satisfy the individuals "needs" whereas hedonic products are accompanied by sensational and experiential effects to satisfy the individuals "wants". Previous studies have over the years has revealed that there is always a hint of a quilt when the product to be purchased is hedonic or has hedonic characteristics as compared to products with utilitarian attributes.. This research seeks to investigates the effect of information quality (i.e., that is a selected different dimension of information quality being completeness, concise representation, consistent representation and free from error given to a potential customer before a purchase is made) which will be in favor of hedonic or utilitarian products. The process in which consumers selecting
\end{abstract}


themselves on whether to purchase the two laptop concepts being Conovo laptop " Hedonic product in this scenario" or the Maximus laptop "Utilitarian product" after the observation of a manipulated detailed specifications of each product. Laptop concepts were used in this study to do away with any bias associated with any distinct laptop brand.

Keywords: Hedonic, Utilitarian, Purchase intention and information quality.

Cite this Article: Mei Qiang, Gyamfi-Yeboah Kwabena, Li Wenyuan, Sikander Ali Qalati, Daria Erusalkina, Hedonic and Utilitarian Orientation Towards the Purchase Intention of Laptop; The Mediating Effect of Information Quality. An Empirical Study of Ghana, International Journal of Management (IJM), 10 (6), 2019, pp. 198-213. http://iaeme.com/Home/issue/IJM?Volume $=10 \&$ Issue $=6$

\section{INTRODUCTION}

After living in the basement of one's family home for years, it then comes to purchasing or renting a new apartment after relocating because of work, how does an individual new to a community decide on opting for the lavish apartment in a rich neighborhood with an exclusive view or going in for an affordable apartment with no view but close to the workplace? If you travel to somewhere exotic for the vacation or stay home and work on a long-term project? Whether to choose between a healthy bowl of salad and an expensive pack of Toblerone chocolate? To watch a documentary to broaden your perspective on new topics or to watch a comedy show for just for the fun of it? Consumers mostly face a cyclic challenge in having to decide between utilitarian and hedonic products that are at least partially driven by emotional desires instead of cold cognitive intuitions.

Prior researches have embellished how various variables takes place before consumer purchase merchandise and how these factors influence their selections. The design of this study is to find out how information quality, after shaped and given to the customer before purchase influences them to either purchase a hedonic or a utilitarian product or perhaps, none. In this study, it predicts that information quality indulges hedonic product more than utilitarian. Buyers are willing and able to have fun when they deem it fit and this is more manageable when the situation warrants them to justify it. This study examines how consumers justify purchase intentions towards utilitarian and hedonic products after the manipulation of information asymmetry depending on how the purchase situation presents itself. A hedonic alternative tends to be rated more highly than a comparable utilitarian alternative in most of the previous studies but none of them has been linked to how the marketers can use information quality to change the outcome or to guide the purchase intentions of consumers to what promotes them and so, that is what this study will be examining. To point out another meaningful variable being information quality. In sum, preferences for utilitarian and hedonic products depend on decision targets as stated by previous studies but information quality changes this reasoning.

Utilitarian and Hedonic considerations is an ordinary decision that impels a purchaser's intent before any choice is made. Taking into consideration the basic selection of new motorcars, for example, one may pay more attention to its utilitarian characteristics (e.g., the gas intake of a vehicle) as well as about its hedonic characteristics (e.g., its elegant shape). Various other studies propose that these different cogitations map onto separate elements of products assessments and viewpoints which allows individualist to differentiate between two different merchandises according to their relative hedonic or utilitarian essential attributes(Asshidin, Abidin, \& Borhan, 2016; Rezaei, Ali, Amin, \& Jayashree, 2016). Hedonic commodities on the whole yields for more exploratory pleasure, utilization and merriment (expensive cars, clothes, watches etc.), Products such as laptops, family vans and microwaves 
are predominantly of its functions and services as elaborated. These foundational tradeoffs should be brought into account based on the purchaser's behavior given the fact the opting for the merchandise characteristics are mostly based on varying appeals(Das, Mukherjee, \& Smith, 2018).

A variety of papers evaluates a purchaser's preference between the two product types, one of which a customer perceives as higher-ranked based on its hedonic aspects and the other perceived as higher- ranked based on a utilitarian aspect". "Setting side by side the preferences for these products in a procurement condition, in which the consumer settles on which of the two to attain, and taking consideration the forfeiture condition, in which the consumer opts for which of the same two items to give up. Based on the literature on the impact of elaboration on message evaluation" (Moon et al., 2017; Vieira, Santini, \& Araujo, 2018), it is suggested that greater spontaneous elaboration in forfeiture choices extents the impact of hedonic features in the all-inclusive assessment. As a result, comparative biased for hedonic regarding, the same utilitarian goods should be much preferred in forfeiture than in acquisition choices.

Prior research leads to believe "why tradeoffs between hedonic and utilitarian dimensions will depend on the task as well". For example, a choice (as opposed to rating) task generally favors the option that is high-ranked in the utilitarian dimension. Tversky and Griffin (Oda, Elvezio, Sukan, Feiner, \& Tversky, 2015; Shafir, Simonson, \& Tversky, 1993) propose that decision-makers in most cases seek for reasons and rationalizations to justify their possible course of action. Similarly, Tversky et al. (2012) manifest that alternatives that provide decision-makers with compelling and justifiable arguments are more likely to be preferred in choice tasks. In line with this view, (Böhm \& Pfister, 1996) show that contexts that foster justification enhance preferences for utilitarian features.

Earlier studies have studied numerous and varying ways by which the everyday consumer can be affected by a purchase or a choice is made. All these papers as dated back all have a similar connection given the fact that they try to understand the variables that influence a purchaser to select a product. Most of these products being a new apartment, a car, an ice cream, the common pen or even a personal laptop falls within the two main different kinds of products which are hedonic and utilitarian based on their derived merits and their characteristics. Forgoing papers mentioned some of these variables which affected a customer's purchase intention selection as power and choice, interactivity, atmospheric effects and so on. Some of these papers will be discussed as followed in order to see the relationship, differences and merits in each situation whereas this study focuses on information quality, that this the different dimensions of information quality of the products specifications before a purchase is made in order to see if there was any significant reaction or effect.

This research adds a significant literature to previous studies because the vast number of papers that tried to link the significant link between information quality and purchase intention used the online survey which is predisposed to survey hoax, not fitting for surveys which ask open-ended questions because there is no qualified interviewer present to meet the hurdles of a large population target or to accurately verify the answers given by the respondents. In this research, the survey was offline and mega-data was used to avoid the above problems. It is also important to note that next to none researches have been able to link the relationship between variables studied in this research. That is how Information quality affects the product types giving marketers the upper hand in knowing how to communicate with customers.

\section{HYPOTHESES DEVELOPMENT}

\subsection{Utilitarian and Hedonic Products and Purchase Intentions}

In a research conducted by (Anderson, Knight, Pookulangara, \& Josiam, 2014) collected data using a national online panel in the year 2013 with a populous of 250 people where they were 
identified as Facebook users who were in regular association with apparel retailers through Facebook pages. An existing modified scale was used in this study to draft the constructs which recorded statistically significant and efficient data which implied that both product type shopping motivations may be important to consumers' purchasing and commitment habits in online. The study, on the other hand, failed to support all the relationships whereas only the correlation between time savings (utilitarian) and purchase intention and the relationships between information access (utilitarian) and experiential shopping (hedonic) and loyalty were supported.In another study by (Kivetz \& Zheng, 2017)where promotion was used to test the purchasing intentions of hedonic and utilitarian products, promotions favored hedonic choices in the high accountability condition and in the control condition which explains that consumers in their natural and clear mind tend to make choices as if they were accountable for, and need to justify, their decisions(Shafir et al., 1993; Simonson \& Nowlis, 2000). They also found that (non-quantity) promotions have a stronger positive effect on hedonic purchases than utilitarian purchases. The following hypothesis is suggested:

H1 - Under the "Hedonic product" condition, information quality expedites positive significant results on purchase intentions.

H2 - Under the "Utilitarian product" condition, information quality will have a definite correlation with purchase intention for consumers who are strongly connected to utilitarian characteristics.

\subsection{Impact of Hedonic/Utilitarian Attributes and Information Quality on Purchase Intentions}

In a study survey by (E. S.-T. Wang, 2017), a sample comprising of more females than males (70.6\% vs. $29.4 \%)$. An under-20 age group (47.7\%) of most of the populous, followed by the 20-29 (43.7\%) and 30-39 (6.9\%) age groups, A study by used participants who generally visited the online store in question less than 6 times a year formed the majority $(71.3 \%)$, followed by those who visited the website $6-10$ times (17.0\%) and $11-15$ times a year $(6.1 \%)$ to assess how a customers perceived product type attribute and information quality affected their intentions towards an online store. In this study, it was ascertained that how customers understood the product type ( hedonic and utilitarian attributes) facilitated their intentions towards the given store.

The study used structural equation modeling (SEM) to evaluate the research framework and confirmatory factor analysis (CFA) for assessing the reliability and convergent validity of the scale items. Additionally, composite reliability (CR) and AVE were used to evaluate reliability and discriminants. To ensure discriminant validity, the square root of each construct's AVE should exceed its factors of correlation with other constructs(Santos-Vijande, López-Sánchez, \& González-Mieres, 2012). The following hypotheses are recognized witht the above in context:

H3 - Consumers' perceived utilitarian attributes of a product positively influence their purchase intentions toeards the product.

H4 - Consumers' perceived hedonic attributes of a product positively influence their purchase intentions towards the product.

\subsection{Information Quality and its Dimensions}

(Lee, Strong, Kahn, \& Wang, 2002), conducted a meta-data analysis to measure and validate the questionnaire of the information quality by employing AIMQ technique. Most importantly, the basis of AIMQ approach is model and combination of dimensions. The authors categorized the dimensions of information quality into two kinds of' product quality and service quality. Additionally, a product-based quality further segmented into two kinds' sound information 
(concise representation, consistent representation, free of error, and completeness) dimensions and useful information (appropriate amount, relevance, understandability, interpretability, and objectivity) dimensions. In contrast, the service-based quality separated as dependable information (e.g. timeliness, and security) dimensions, and usable information (believability, accessibility, ease of operation, and reputation) dimensions. This scholar used sound information dimensions of the product based information quality. (Mashoufi, Ayatollahi, \& Khorasani-Zavareh, 2019), conducted a study in 2017 based to analyze the quality of data of emergency care services in Iran. The sample size of the study was 234 comprises of the (e.g. heads, experts, and nurses of emergency care and disaster management departments and centers. The results of the study supported the positive relationship between all the dimensions and information quality. Yet, the authors conclude that overall information quality is not at a high level in emergency care services, but they are improving. Interestingly, most recent studies supported the positive relationship of several dimensions with information quality include (Bozan \& Berger, 2018; Demoulin \& Coussement, 2018; Shahbazi, Farajpahlou, Osareh, \& Rahimi, 2019; Yamsaengsung \& Papasratorn, 2018). Thus, the following hypotheses suggested:

H5 ( $a, b, c$, and d) - Dimensions of concise representation, consistent representation, free of error, and completeness has significant influence on information quality.

\subsection{Information Quality and Purchase Intention}

(Lee et al., 2002), conducted a quantitative study of 173 young respondents of Hong Kong cosmetic industry, found a positive association among information quality and purchase intention. Indeed, the authors used information quality as mediator among electronic word of mouth and purchase intention of smartphones. Additionally, (Danniswara, Sandhyaduhita, \& Munajat, 2020), a study of 350 respondents of Indonesia, found the positive relationship between electronic word of mouth, celebrity endorsement, brand satisfaction, brand trust, information quality and purchase intention. Interestingly, an information adoption model (IAM), which comprises of information credibility, quality, usefulness and adoption. The two consecutive studies conducted the first impacts of online reviews on purchase intention and second with detailed interviews. The authors of the study, conclude that information quality, quantity, dedication has a significant influence on purchase intention (Erkan \& Evans, 2018). Even though, information quality is an antecedents to purchase intention (C.-C. Chen \& Chang, 2018). Thus, following hypothesis proposed:

H6 - Information quality has significant influence on purchase intention of laptops.

\subsection{The Mediating Role of Information Quality}

From the perspective of consumers (R. Y. Wang \& Strong, 1996), defined quality of information as "meeting user needs according to external, subjective user perceptions". In addition, (Wand \& Wang, 1996), suggests the "information that results from the process or the system should correctly represent the real-world view of interest to the user." Furthermore, (Radulovic, Mihindukulasooriya, García-Castro, \& Gómez-Pérez, 2018), conclude that accurate information is vital for making particular decision related to buying, it's the foundation for measuring the quality of the product. Interestingly, the mediating role of information quality initiated by (Preuss, 2003). The author, study of 182 respondents nurses working in acute-care hospitals in Minnesota. The results of the study conclude the positive mediation of information quality between the relationship of employee knowledge, work design, and total quality management and organizational performance. (P. Hong, Youn, \& Nahm, 2008), study of 60 supply chain firms based in Korea, found the positive mediation of information quality among the supply chain partnership and information sharing. In contrast, (Marinagi, Trivellas, \& 
Reklitis, 2015), study of 61 manufacturing firms of Greece, employed information sharing as mediator among the information quality and supply chain facilities. Apart from this, (Lam, Lau, Cheng, \& Wong, 2019), administered the three mediators in the study (e.g. social media browsing intension, electronic word of mouth, information credibility/quality) between the hedonic, utilitarian and purchase intention in cosmetic industry of Hong Kong. As well as (Chang, Hsu, Chen, \& Kuo, 2019; Laumer, Maier, \& Weitzel, 2017; Priyadarshini, Sreejesh, \& Anusree, 2017; Yusuf, Che Hussin, \& Busalim, 2018), suggested the mediation of information quality. As consequences of, above literature, we propose following hypotheses:

H7 - Information quality significantly mediate relationship between hedonic and purchase intention.

H8 - Information quality significantly mediate relationship between Utilitarian and purchase intention.

\section{RESEARCH METHODOLOGY}

\subsection{Sample and Data Collection Process}

A non-probability sampling approach was employed in the present study. This approach is favored by numerous scholars, it is considered a common approach in (Getz \& Brown, 2006). Utilization of random sampling method is normally difficult in customer studies, when the population is too large (Chou, $\mathrm{Lu}, \&$ Chang, 2014). The data were collected from December 2018 to March 2019. A self-administered questionnaire was used for data collection. This study employed the quantitative approach of research. A convenience sampling approach utilized to reach the customers who are ease to access (Usakli \& Baloglu, 2011). Customers were reached randomly rather than reaching all customers in a systematic way. The respondents assured that their participation would remain voluntary, confidential, and anonymous.

For surety of the accurate hypothetical structure, an instrument was administered into two languages Twi as well as English. The reason involves the local Ghanaian customers. The two pilot study conducted with 80 customers each time, pilots study conducted in Accra and Kumasi. To guarantee non-response bias an independent samples t-test was administered as per (Armstrong \& Overton, 1977) proposition. In order to ensure a high response rate, questionnaires were filled and get back onsite. In total 1364 questionnaire were distributed, after excluding all the incomplete and missing information 1238 respondents responses used for data analysis. The accurate and valid response rate of the study was $90.7 \%$

\subsection{Respondents Information}

The present study states that $(59.6 \%=738)$ of respondents were male and $(40.4 \%=500)$ were male. Most of the customers were students $(39.1 \%=484)$ they were studying in capital of country, followed by entrepreneurs $(28.5 \%=353)$, business executives In response to age $(36.02 \%=446)$ fall in the range of 18 and $25,(42.97 \%=532)$ fall in the range of 26 and 35 , $(11.71 \%=145)$ fall in the range of 36 and 45 , and rest of $(9.28 \%=115)$ fall in the age of $>45$. More specifically $462(63.57 \%=787)$ of the respondents were married, and rest of $(36.42 \%=451)$ were married. Taking into consideration the education of respondents out of 1238 , approximately $(4.2 \%=52)$ just had elementary education $(48.15 \%=596)$ were undergraduates, $(33.52 \%=415)$ masters and $(14.13 \%=175)$ were postgraduate. Their family income range from $<$ GHS $5000 /=(35.0 \%=434)$, GHS 5000 to $10,000(30.2 \%=375)$, and remaining have $>$ GHS $14,000(34.75 \%=429)$. In response to occupation, $(34.0 \%=421)$ are students, $(41.03 \%=508)$ work in the private sector, $(16.39 \%=203)$ are in government and rest of $(8.56 \%=106)$ works in manufacturing and another sector. 
Hedonic and Utilitarian Orientation Towards the Purchase Intention of Laptop; The Mediating Effect of Information Quality. An Empirical Study of Ghana

\subsection{Measures of the Study}

The 15 items administered to measure an information quality of product. An instrument adapted from (Lee et al., 2002), this instrument cover four dimensions of the product based information quality (Concise representation, consistent representation, completeness and free of error). To assess purchase intention, we adopted 4 items scale from the scholarship of (Bukhari et al., 2013). Respondent was asked to answer "I would intend to buy quality laptop", "I would actively seek those laptop that have high perceived value", "My willingness to buy quality laptop is high", "I have intention to buy quality laptop". To assess the hedonic and utilitarian 5 items scale adopted from the work of (Voss, Spangenberg, \& Grohmann, 2003), the scale was modified as per this study based on product quality perspective. Thus, related to hedonic respondents were asked whether product is providing "Not fun/fun", "Dull/exciting", "Not delightful/delightful", "Not thrilling/thrilling", "and Enjoyable/unenjoyable". In contrast related to utilitarian, they were asked whether product is "Effective/ineffective", "Helpful/unhelpful", "Functional/not functional", "Necessary/unnecessary", "and Practical/impractical". All of the scale were rated on five-point Likert scale $1=$ strongly disagree, $2=$ disagree, $3=$ neutral, $4=$ agree, and $5=$ strongly Agree.

\section{RESULT ANALYSIS}

For analysis of the results partial least square structural equation modeling (PLS-SEM) utilized. Several tests particularly related to reliability, validity and path coefficients, as well as to ensure the data free from multicollinearity and other data related bias were measured (Joseph F Hair, Black, Babin, \& Anderson, 2010). This analysis section used a two-way approach to assess the results.

Assessment of measurement model and (2) Structural model, (Joseph F Hair et al., 2010).

\subsection{An assessment of the Measurement Model}

As per (Henseler, Ringle, \& Sinkovics, 2009) suggestions in order to measure the model of study scholars are required to assess the "individual item reliability, internal consistency, content validity, convergent validity, and discriminant validity".

Individual item reliability. Measured by taking into account the outer loadings of items related to a particular dimension (Joseph F Hair, Sarstedt, Pieper, \& Ringle, 2012). (Hair Jr, Hult, Ringle, \& Sarstedt, 2016), recommended that it should be retained between 0.40 and 0.70 . Hence as demonstrated in Table 1 all the values adequately satisfied and meet the standards, items values noted in the range of 0.665 and 0.867 .

As per the rule of thumb set by (Nunnally 1978), the value of Cronbach's Alpha should be greater than 0.7. As displayed in Table 1 the values of CA falls in the range of 0.756 to 0.881 , therefore, it is concluded that the present study adequately meets the standard of reliability of the measures.

Internal consistency reliability. (Bagozzi \& Yi, 1988) rule of thumb stated that the value of composite reliability should be equivalent to or greater than 0.7 . Table 1 reflects the coefficient value of CR of the constructs, as displayed in mentioned table values' falls in the range of 0.836 to 0.918 , suggesting the adequate reliability of the measures.

Convergent validity. As per (Fornell \& Larcker, 1981), rule of thumb the value of AVE, should be equivalent to 0.5 or above. The value of AVE of the present study as reflected in Table 1 falls in the range of 0.508 to 0.737 henceforth, it is concluded that this study demonstrated the satisfactory level of convergent validity.

Discriminant validity. Two methods were used to evaluate the "discriminant validity" of the variables. 1) It was ensured that the cross-loadings of indicators should be greater than any 
other opposing constructs (Hair, et al. 2012). 2) According to the Fornell and Larcker (1981) criterion, the square root of AVE for each construct should exceed the inter-correlations of the construct with other model constructs". Hence, as reflected in Table 2. Both approaches ensured the satisfaction of the results and validity.

\subsection{An Assessment of the Structural Model}

This article utilized PLS bootstrapping with 2000 bootstraps and 1238 cases with the motive to enlighten the path coefficients and their significance (Henseler et al., 2009). Table 3, and Figure 1 demonstrate the comprehensive depiction of evaluations of the structural model alongside with statistics related to mediation of information quality.

In order to evaluate the variance of the measures, PLS-SEM suggest evaluating the $\mathrm{R}^{2}$ coefficient which also called coefficient of determination (Joe F Hair, Ringle, \& Sarstedt, 2011). According to (Cohen, 1998), the value of $\mathrm{R}^{2} 0.60,0.33$ and 0.19 respectively set as rule of thumb and these values described as substantial, moderate and weak. (Joseph F Hair et al., 2010), proposed that the $\mathrm{R}^{2}$ coefficient is subject to the situation where a specific study is conducted. Yet, as per (Falk \& Miller, 1992), recommendation $\mathrm{R}^{2}$ coefficients of 0.10 is also acceptable. Meanwhile, as reflected in Table 5 the present study $\mathrm{R}^{2}$ noted was in the range of 0.170 and 0.758 .

Predictive relevance of the model. Keeping in view the reflective nature of measures, this study employed cross-validated redundancy measure $\mathrm{Q}^{2}$, for evaluating the model as per suggestions of (Ringle, Sarstedt, \& Straub, 2012). It is an indicator of the model's out-of-sample predictive power or predictive relevance given by (Geisser, 1974; Stone, 1974) $Q^{2}$ value. In the structural equation model, $\mathrm{Q}^{2}$ values larger than zero for a specific reflective endogenous latent variable indicate the path model's predictive relevance for a particular dependent construct. Moreover, As a relative measure of predictive relevance, q2 values of $0.02,0.15$, and 0.35 , respectively, indicate that an exogenous construct has a small, medium, or large predictive relevance for a certain endogenous construct. Hence, as reflected in Table 4 the results of the study shows that model has small (Completeness), medium (Information quality and purchase intention), and large (Concise and consistent representation) predictive relevance.

Table 1: Measurement model

\begin{tabular}{|c|c|c|c|c|c|}
\hline Constructs & Factor Loadings & Items & CA & CR & AVE \\
\hline Completeness & Completness1 & 0.874 & 0.784 & 0.873 & 0.697 \\
\hline & Completness2 & 0.835 & & & \\
\hline & Completness3 & 0.793 & & & \\
\hline Concise & Concise-R1 & 0.873 & 0.881 & 0.918 & 0.737 \\
\hline Representation & Concise-R2 & 0.827 & & & \\
\hline & Concise-R3 & 0.867 & & & \\
\hline & Concise-R4 & 0.867 & & & \\
\hline Consistent & Consistent-R1 & 0.806 & 0.839 & 0.892 & 0.675 \\
\hline Representation & Consistent-R2 & 0.839 & & & \\
\hline & Consistent-R3 & 0.859 & & & \\
\hline Free of Error & Consistent-R4 & 0.779 & & & \\
\hline & Foe1 & 0.714 & 0.763 & 0.849 & 0.586 \\
\hline & Foe2 & 0.702 & & & \\
\hline Foe3 & 0.825 & & & \\
\hline & Foe4 & 0.813 & & & \\
\hline & Hedonic1 & 0.583 & 0.756 & 0.836 & 0.508 \\
\hline & Hedonic2 & 0.665 & & & \\
\hline
\end{tabular}


Hedonic and Utilitarian Orientation Towards the Purchase Intention of Laptop; The Mediating Effect of Information Quality. An Empirical Study of Ghana

\begin{tabular}{|c|c|c|c|c|c|}
\hline & Hedonic4 & 0.779 & & & \\
\hline & Hedonic5 & 0.758 & & & \\
\hline Purchase & PI1 & 0.803 & 0.792 & 0.862 & 0.610 \\
\hline Intention & PI2 & 0.801 & & & \\
\hline & PI3 & 0.804 & & & \\
\hline & PI4 & 0.711 & & & \\
\hline Utilitarian & Utaletarian1 & 0.788 & 0.846 & 0.890 & 0.619 \\
\hline & Utaletarian2 & 0.800 & & & \\
\hline & Utaletarian3 & 0.745 & & & \\
\hline & Utaletarian4 & 0.780 & & & \\
\hline & Utaletarian5 & 0.818 & & & \\
\hline
\end{tabular}

Table 2. Latent variable correlation and square root of AVE

\begin{tabular}{|c|c|c|c|c|c|c|c|}
\hline & $\mathbf{1}$ & $\mathbf{2}$ & $\mathbf{3}$ & $\mathbf{4}$ & $\mathbf{5}$ & $\mathbf{6}$ & $\mathbf{7}$ \\
\hline Completeness & 0.835 & & & & & & \\
\hline Concise Representation & 0.105 & 0.859 & & & & & \\
\hline Consistent Representation & 0.225 & 0.649 & 0.821 & & & & \\
\hline Free of Error & 0.238 & 0.299 & 0.454 & 0.766 & & & \\
\hline Hedonic & 0.677 & 0.147 & 0.292 & 0.419 & 0.713 & & \\
\hline Purchase Intention & 0.335 & 0.343 & 0.412 & 0.621 & 0.364 & 0.781 & \\
\hline Utilitarian & 0.238 & 0.424 & 0.515 & 0.678 & 0.428 & 0.63 & 0.786 \\
\hline
\end{tabular}

Table 3. Path coefficients and hypotheses testing

\begin{tabular}{|c|c|c|c|c|c|c|c|}
\hline Hypotheses & Relationship & $\begin{array}{c}\text { Path } \\
\text { Coefficient }\end{array}$ & Mean & S.D & t-value & $\begin{array}{c}\text { p- } \\
\text { value }\end{array}$ & Decision \\
\hline \multicolumn{8}{|l|}{ Direct } \\
\hline H1 & $\begin{array}{c}\text { Hedonic -> Information } \\
\text { Quality }\end{array}$ & 0.195 & 0.196 & 0.026 & 7.489 & 0.000 & Supported \\
\hline H2 & $\begin{array}{c}\text { Utilitarian -> Information } \\
\text { Quality }\end{array}$ & 0.625 & 0.625 & 0.025 & 25.135 & 0.000 & Supported \\
\hline H3 & $\begin{array}{l}\text { Hedonic -> Purchase } \\
\text { Intention }\end{array}$ & 0.116 & 0.117 & 0.027 & 4.384 & 0.018 & Supported \\
\hline H4 & $\begin{array}{c}\text { Utilitarian -> Purchase } \\
\text { Intention }\end{array}$ & 0.58 & 0.58 & 0.022 & 26.66 & 0.000 & Supported \\
\hline H5 (a) & $\begin{array}{c}\text { Information Quality -> } \\
\text { Completeness }\end{array}$ & 0.413 & 0.414 & 0.034 & 12.095 & 0.000 & Supported \\
\hline H5 (b) & $\begin{array}{l}\text { Information Quality -> } \\
\text { Concise Representation }\end{array}$ & 0.782 & 0.783 & 0.014 & 54.201 & 0.000 & Supported \\
\hline H5 (c) & $\begin{array}{l}\text { Information Quality -> } \\
\text { Consistent Representation }\end{array}$ & 0.871 & 0.871 & 0.008 & 113.504 & 0.000 & Supported \\
\hline H5 (d) & $\begin{array}{c}\text { Information Quality -> Free } \\
\text { of Error }\end{array}$ & 0.713 & 0.713 & 0.02 & 36.038 & 0.000 & Supported \\
\hline H6 & $\begin{array}{l}\text { Information Quality -> } \\
\text { Purchase Intention }\end{array}$ & 0.28 & 0.281 & 0.03 & 9.302 & 0.000 & Supported \\
\hline \multicolumn{8}{|l|}{ Indirect } \\
\hline H7 & $\begin{array}{c}\text { Hedonic -> Information } \\
\text { Quality -> PI }\end{array}$ & 0.055 & 0.055 & 0.01 & 5.539 & 0.000 & Supported \\
\hline H8 & $\begin{array}{c}\text { Utilitarian -> Information } \\
\text { Quality -> PI }\end{array}$ & 0.175 & 0.176 & 0.021 & 8.312 & 0.000 & Supported \\
\hline
\end{tabular}

Table - 4. Cross Validated Redundancy 


\begin{tabular}{|c|c|c|c|c|}
\hline & SSO & SSE & $\mathbf{Q}^{\mathbf{2}}(=\mathbf{1 - S S E} / \mathbf{S S O})$ & Decision \\
\hline Completeness & $3,714.00$ & $3,311.22$ & 0.108 & Small \\
\hline Concise Representation & $4,952.00$ & $2,858.09$ & 0.423 & Large \\
\hline Consistent Representation & $4,952.00$ & $2,562.33$ & 0.483 & Large \\
\hline Free of Error & $4,952.00$ & $3,558.43$ & 0.281 & Medium \\
\hline Hedonic & $6,190.00$ & $6,190.00$ & & \\
\hline Information Quality & $18,570.00$ & $15,469.65$ & 0.167 & Medium \\
\hline Purchase Intention & $4,952.00$ & $3,804.89$ & 0.232 & Medium \\
\hline Utilitarian & $6,190.00$ & $6,190.00$ & & \\
\hline
\end{tabular}

Table 5. Coefficient of determination

\begin{tabular}{|c|c|c|c|}
\hline & R Square & R Square Adjusted & Decision \\
\hline Completeness & 0.170 & 0.160 & Weak \\
\hline Concise Representation & 0.612 & 0.611 & Substantial \\
\hline Consistent Representation & 0.759 & 0.758 & Substantial \\
\hline Free of Error & 0.508 & 0.507 & Moderate \\
\hline Information Quality & 0.533 & 0.532 & Moderate \\
\hline Purchase Intention & 0.444 & 0.443 & Moderate \\
\hline
\end{tabular}

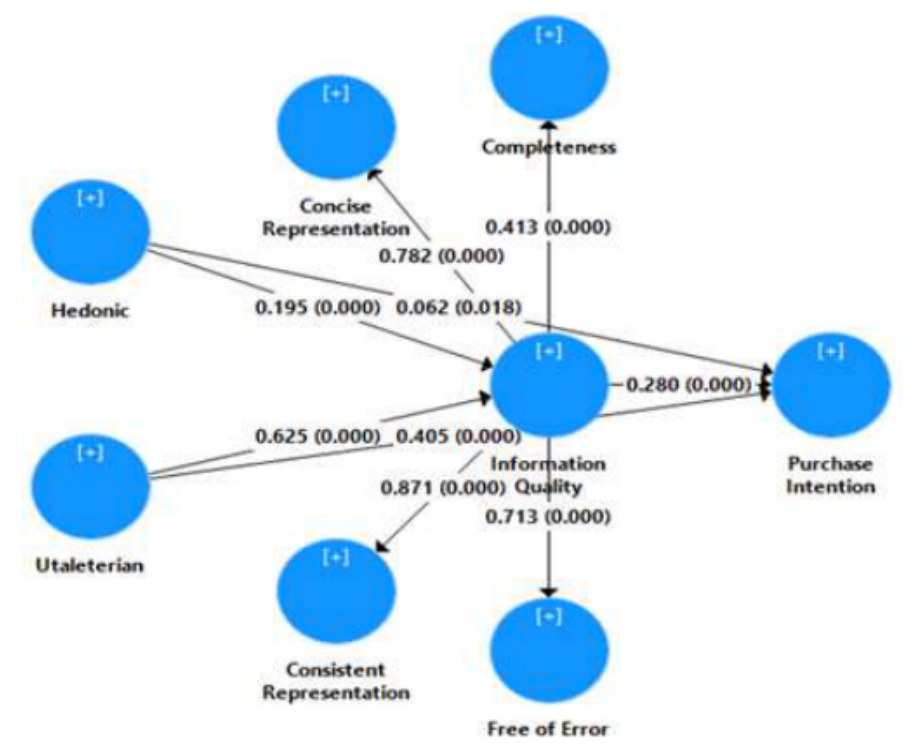

Figure 1 Conceptual framework

\section{DISCUSSION AND CONCLUSION}

After the analyses and its explanations, it is safe to say that information quality has a significant effect on the purchase intentions of both product types. This finding shows it is important to give a detailed and more/high level of information to customers mostly when the product in concern has hedonic characteristics and also classified as a high involvement product. Highinvolvement purchases. Can be elaborated as the complex buying behaviour occurs when the consumer is highly involved with the purchase and when there are significant differences between brands(Karimi, Papamichail, \& Holland, 2015). This behaviour can be associated with the purchase of a new home or a personal computer. 
As you have seen, many factors influence a consumer's behaviour or purchase intentions. Depending on a consumer's experience and knowledge, some consumers may be able to make quick purchase decisions which are often the case of utilitarian products and other consumers may need to get information and be more involved in the decision process before making a purchase which in this case relates positively to products with hedonic characteristics(Akbari, 2015). The level of involvement reflects how personally important or interested you are in consuming a product and how much information you need to make a decision. The level of involvement in buying decisions may be considered a continuum from fairly routine decisions (consumers are not very involved) in decisions that require extensive thought and a high level of involvement. Whether a decision is low, high, or limited, involvement varies by the consumer, not by product, although some products such as purchasing a house typically require a high-involvement for all consumers(I. B. Hong, 2015). Consumers with no experience purchasing a product may have more involvement than someone who is replacing a product.

Buyers oftentimes engage in conventional response behaviour when they make lowinvolvement decisions that are, they make automatic purchase decisions based on limited information or information they have gathered in the past whereas in this study the participants who chose the utilitarian product were not significantly affected by the level of information and other moderating variables such as the response time and their gender. For example, if you always order or purchase a Maximus E-book, you're always going to purchase it because your routine is to order or purchase from the Maximus manufacture, and you simply do it(Srinivasan, Rutz, \& Pauwels, 2016). Similarly, if you own a Maximus E-book at home, you may buy more without any information search.

Some low-involvement purchases are made with no planning or previous thought. These buying decisions are called impulse buying. While you're waiting to check out at the grocery store, perhaps you see a magazine with Angelina Jolie and Brad Pitt on the cover and buy it on the spot simply because you want it and the level of information does not matter to you(Pansari $\&$ Kumar, 2017). You might see a roll of tape at a check-out stand and remember you need one or you might see a bag of chips and realize you're hungry or just want them. These are items that are typically low-involvement decisions. Low-involvement decisions aren't necessarily products purchased on impulse, although they can be. It is important to state that this can be the fact for both product types but in the case of adding information asymmetry, this is barely the case for hedonic products.

By contrast, high-involvement decisions carry a higher risk to buyers if they fail, are complex, and/or have high price tags. A car, a house, and an insurance policy are examples. These items are not purchased often but are relevant and important to the buyer(Kim \& Woo, 2016). Buyers don't engage in routine response behavior when purchasing high-involvement products. Instead, consumers engage in what's called extended problem solving, where they spend a lot of time comparing different aspects such as the features of the products, prices, and warranties.

High-involvement decisions can cause buyers a great deal of post-purchase dissonance (tension) if they are unsure about their purchases or if they had a difficult time deciding between two alternatives. Companies that sell high-involvement products are aware that post-purchase dissonance can be a problem. Oftentimes, they try to offer purchasers a lot of knowledge about their products, including why they are superior to competing brands and how they won't let the consumer down. Salespeople may be utilized to answer questions and do a lot of customer "hand-holding." 


\section{RESEARCH IMPLICATIONS}

\subsection{Hedonic Implications}

To continue with, this research commenced to find a great significance between information quality and hedonic products because of factors such as its defining characteristics which attract hedonic motivation. "The term motivation comes from the same Latin stem "mot-" (meaning "move") as does the term emotion. The term motive applies to any internal force that activates and gives direction to behavior". This motivation is the influence of a purchaser's pleasure and pain receptors affecting that of their willingness to move towards a particular goal or to evade a threat(Kivetz \& Zheng, 2017; Lu, Liu, \& Fang, 2016). In this given scenario provided by this study, hedonic motivation guided purchasers to either wanting to buy or not buy at all. People approach pleasure and avoid pain as the old classic principle states which adequately links to the above-explained. This motivation is mostly evoked when potential customers act on certain behaviors that resulted from emotional and aesthetic feelings such as love, joy, hate etc. which goes hand in hand with hedonic characteristics which can be thought as a measure that ranges from good to bad and the primary motive is for individuals to keep this gauge as close to good as possible(Klein \& Melnyk, 2016). In 1969, American psychologist Jacob Levine suggested that the motivational hedonic theory is based "solely on experimental evidence that employed three basic research models to explain motivational (i.e., goal-directed, drive-energized behaviors) sources of humor: cognitive-perceptual theory" (involves the resolution of incongruities); behavior theory (emphasizes the stimulus-response aspects of learning and the reduction of basic drives); and psychoanalytic theory(Das et al., 2018). The use of information quality in this research fully acknowledged the use of stimuli-response by the guidance of the varying dimensions of information quality to randomly selected individuals which fully supported the hedonic product.

It is greatly understandable that was the situation because of the array of emotions and time individuals invest in hedonic merchandises henceforth them wanting the detailed information concerning the product before purchase. This does not only satisfy their expectations but makes the product a worth-while purchase.

\subsection{Utilitarian Implications}

Whereas "hedonic products are desirable objects that allow the individual to feel enjoyment, fun and pleasure from the purchase" of a particular product and consumed for its luxury purposes, it is different for that of utilitarian products because they are bought for practical usage and always based on the individual's needs. They are products that most of the time associates itself with no guilt because it is deemed needful and justifies its purpose as not luxurious(Arruda-Filho \& Biffignandi, 2016; Zheltukhina, Krasavsky, Slyshkin, \& Ponomarenko, 2016).

With this said, one can imagine that a purchaser does not need to be affected by the dimensions of information before they purchase a utilitarian product mostly because they mostly have a solid idea of what they need the product for even before a purchase is made mostly because there are no emotional sensations affiliated to the purchase but only a cognitive one(Oliveira- Castro, Cavalcanti, \& Foxall, 2016). "The consumer is generally less willing to spend more on utilitarian items" Maximus laptop" in this study because they can rationalize that this item is less enjoyable mainly because utilitarian goods are items bought out of necessity and don't necessarily bring any joy to the consumer and might be purchased very frequently(S. Chen, Thomas, \& Kohli, 2016), which allows the buyer to be more price sensitive towards this item".

In relationship to utilitarian purchase intentions and information quality, there was a significant response when customers were exposed to information quality before the purchase 
Hedonic and Utilitarian Orientation Towards the Purchase Intention of Laptop; The Mediating Effect of Information Quality. An Empirical Study of Ghana

was to be made. Hence the assumption for a negative relation because customers only wanted the product to attain a particular and specific need which had no emotional attachments and in most cases already had in mind what they expected from the utilitarian product was eradicated in this study.

\section{REFERENCES}

[1] Akbari, M, Different impacts of advertising appeals on advertising attitude for high and low involvement products. Global Business Review, 16(3), 2015, pp 478-493.

[2] Anderson, K. C., Knight, D. K., Pookulangara, S., \& Josiam, B, Influence of hedonic and utilitarian motivations on retailer loyalty and purchase intention: a facebook perspective. Journal of Retailing and Consumer Services, 21(5), 2014, pp 773-779.

[3] Armstrong, J. S., \& Overton, T. S, Estimating nonresponse bias in mail surveys. Journal of marketing research, 14(3), 1977, pp 396-402.

[4] Arruda-Filho, E. J. M., \& Biffignandi, S, Utilitarian characteristics reducing guilt: perceived values in the justification of choice. International Journal of Information Technology and Management, 15(2), 2016, pp 168-194.

[5] Asshidin, N. H. N., Abidin, N., \& Borhan, H. B, Perceived quality and emotional value that influence consumer's purchase intention towards American and local products. Procedia Economics and Finance, 35, 2016, pp 639-643.

[6] Bagozzi, R. P., \& Yi, Y, on the evaluation of structural equation models. Journal of the academy of marketing science, 16(1), 1988, pp 74-94.

[7] Böhm, G., \& Pfister, H.-R, Instrumental or emotional evaluations: What determines preferences? Acta Psychologica, 93(1-3), 1996, pp 135-148.

[8] Bozan, K., \& Berger, A, The Effect of Unmet Expectations of Information Quality on PostAcceptance Workarounds among Healthcare Providers. Paper presented at the Proceedings of the 51st Hawaii International Conference on System Sciences, 2018

[9] Bukhari, F. A., Rizwan, M., Liaquat, K., Ashraf, R., Ali, S. M., Azeem, S. R., Ali, M. A. , An investigation of customers to explain the purchase intentions for expensive mobile phone. Journal of Basic and Applied Scientific Research, 3(11), 2013, pp 87-96.

[10] Chang, K.-C., Hsu, C.-L., Chen, M.-C., \& Kuo, N.-T. How a branded website creates customer purchase intentions. Total Quality Management \& Business Excellence, 30(3-4), 2019, pp 422-446.

[11] Chen, C.-C., \& Chang, Y.-C, What drives purchase intention on Airbnb? Perspectives of consumer reviews, information quality, and media richness. Telematics and Informatics, 35(5), 2018, pp 1512-1523.

[12] Chen, S., Thomas, S., \& Kohli, C, What Really Makes a Promotional Campaign Succeed on a Crowdfunding Platform?: Guilt, Utilitarian Products, Emotional Messaging, And Fewer But Meaningful Rewards Drive Donations. Journal of Advertising Research, 56(1), 2016pp 81-94.

[13] Chou, P.-F., Lu, C.-S., \& Chang, Y.-H, Effects of service quality and customer satisfaction on customer loyalty in high-speed rail services in Taiwan. Transportmetrica A: Transport Science, 10(10), 2014, pp 917-945.

[14] Cohen, J, Statistical Power Analysis for the Behavioural Sciences, xxi. In: Hillsdale, NJ: L Erlbaum associates, 1998

[15] Danniswara, R., Sandhyaduhita, P., \& Munajat, Q, The impact of EWOM referral, celebrity endorsement, and information quality on purchase decision: A case of Instagram. In Global Branding: Breakthroughs in Research and Practice IGI Global, 2020, pp 882 - 905

[16] Das, G., Mukherjee, A., \& Smith, R. J, The perfect fit: The moderating role of selling cues on hedonic and utilitarian product types. Journal of Retailing, 94(2), 2018, pp 203-216.

[17] Demoulin, N. T., \& Coussement, K, Acceptance of text-mining systems: The signaling role of information quality. Information \& management, 2018 
[18] Erkan, I., \& Evans, C, Social media or shopping websites? The influence of eWOM on consumers' online purchase intentions. Journal of Marketing Communications, 24(6), 2018, pp 617-632.

[19] Falk, R. F., \& Miller, N. B, A primer for soft modeling: University of Akron Press, 1992

[20] Fornell, C., \& Larcker, D. F, Evaluating structural equation models with unobservable variables and measurement error. Journal of marketing research, 18(1), 1981, pp 39-50.

[21] Geisser, S, A predictive approach to the random effect model. Biometrika, 61(1), 1974, pp 101107.

[22] Getz, D., \& Brown, G, Critical success factors for wine tourism regions: a demand analysis. Tourism Management, 27(1), 2006, pp 146-158.

[23] Hair, J. F., Black, W. C., Babin, B. J., \& Anderson, R. E, Multivariate data analysis: Global edition. In: Pearson Higher Education Upper Saddle River, NJ, 2010

[24] Hair, J. F., Ringle, C. M., \& Sarstedt, M, PLS-SEM: Indeed a silver bullet. Journal of Marketing theory and Practice, 19(2), 2011, pp 139-152.

[25] Hair, J. F., Sarstedt, M., Pieper, T. M., \& Ringle, C. M, The use of partial least squares structural equation modeling in strategic management research: a review of past practices and recommendations for future applications. Long range planning, 45(5-6), 2012, pp 320-340.

[26] Hair Jr, J. F., Hult, G. T. M., Ringle, C., \& Sarstedt, M, A primer on partial least squares structural equation modeling (PLS-SEM): Sage publications, 2016

[27] Henseler, J., Ringle, C. M., \& Sinkovics, R. R, The use of partial least squares path modeling in international marketing. In New challenges to international marketing, Emerald Group Publishing Limited, 2009, pp. 277-319

[28] Hong, I. B, Understanding the consumer's online merchant selection process: The roles of product involvement, perceived risk, and trust expectation. International Journal of Information Management, 35(3), 2015, 322-336.

[29] Hong, P., Youn, S., \& Nahm, A, Supply chain partnerships and supply chain integration: the mediating role of information quality and sharing. International Journal of Logistics Systems and Management, 4(4), 2008, pp 437-456.

[30] Karimi, S., Papamichail, K. N., \& Holland, C. P, The effect of prior knowledge and decisionmaking style on the online purchase decision-making process: A typology of consumer shopping behaviour. Decision Support Systems, 77, 2015, pp 137-147.

[31] Kim, Y. G., \& Woo, E, Consumer acceptance of a quick response (QR) code for the food traceability system: Application of an extended technology acceptance model (TAM). Food Research International, 85, 2016, pp 266-272.

[32] Kivetz, R., \& Zheng, Y, The effects of promotions on hedonic versus utilitarian purchases. Journal of Consumer Psychology, 27(1), 2017, pp 59-68.

[33] Klein, K., \& Melnyk, V, Speaking to the mind or the heart: effects of matching hedonic versus utilitarian arguments and products. Marketing Letters, 27(1), 2016, pp 131-142.

[34] Lam, A. Y., Lau, M. M., Cheng, C., \& Wong, M. Y, The impact of electronic word-of-mouth on young consumers' purchase intention in Hong Kong. Paper presented at the Proceedings of the 10th International Conference on E-Education, E-Business, E-Management and E-Learning, 2019

[35] Laumer, S., Maier, C., \& Weitzel, T, Information quality, user satisfaction, and the manifestation of workarounds: a qualitative and quantitative study of enterprise content management system users. European Journal of Information Systems, 26(4), 2017, pp 333-360.

[36] Lee, Y. W., Strong, D. M., Kahn, B. K., \& Wang, R. Y, AIMQ: a methodology for information quality assessment. Information \& management, 40(2), 2002, pp 133-146.

[37] Lu, J., Liu, Z., \& Fang, Z, Hedonic products for you, utilitarian products for me. Judgment \& Decision Making, 11(4), 2016

[38] Sakthirama.V and Dr. R.Venkatram, A Structural Analysis of Purchase Intention of Organic Consumers, International Journal of Management (IJM), Volume 3, Issue 2, May-August (2012) 
Hedonic and Utilitarian Orientation Towards the Purchase Intention of Laptop; The Mediating Effect of Information Quality. An Empirical Study of Ghana

[39] Marinagi, C., Trivellas, P., \& Reklitis, P, Information quality and supply chain performance: The mediating role of information sharing. Procedia-Social and Behavioral Sciences, 175, 2015, pp 473-479.

[40] Mashoufi, M., Ayatollahi, H., \& Khorasani-Zavareh, D, Data Quality Assessment in Emergency Medical Services: What Are the Stakeholders' Perspectives? Perspectives in health information management, 16(Winter), 2019

[41] Sanjeev Pandey and Dr. Sandeep Srivastava. A Study on Determinants of Customer Purchase Intention in Healthcare Product - A Case of General Medical Equipment in India. Journal of Management, 4(2), 2017, pp. 19-30.

[42] Moon, M., Khalid, M., Awan, H., Attiq, S., Rasool, H., \& Kiran, M, Consumer's perceptions of website's utilitarian and hedonic attributes and online purchase intentions: A cognitive-affective attitude approach. Spanish Journal of Marketing-ESIC, 21(2), 2017, pp 73-88.

[43] Oda, O., Elvezio, C., Sukan, M., Feiner, S., \& Tversky, B, Virtual replicas for remote assistance in virtual and augmented reality. Paper presented at the Proceedings of the 28th Annual ACM Symposium on User Interface Software \& Technology, 2015

[44] Shah Suraj Manojkumar and Dr. Mahendra S. Sharma, An Empirical Study to Measure the Effect of Brand Loyalty and Skepticism on Purchase Intention with Reference to Cause Related Marketing in Ahmedabad City. Journal of Management, 5(2), 2018, pp. 1-12.

[45] Oliveira-Castro, J. M., Cavalcanti, P. R., \& Foxall, G. R, What consumers maximize: brand choice as a function of utilitarian and informational reinforcement. Managerial and Decision Economics, 37(4-5), 2016, pp 360-371.

[46] Pansari, A., \& Kumar, V, Customer engagement: the construct, antecedents, and consequences. Journal of the Academy of Marketing Science, 45(3), 2017, pp 294-311.

[47] Preuss, G. A, High performance work systems and organizational outcomes: The mediating role of information quality. ILR Review, 56(4), 2003, pp 590-605.

[48] E. Pradeep, Dr. V. M. Shenbagaraman and Dr. P. Saravanan, Analysis of Customer Attitude Factors Towards Online Purchase Intentions of Baby Products in Chennai. International Journal of Civil Engineering and Technology, 9(8), 2018, pp. 1477-1484

[49] Priyadarshini, C., Sreejesh, S., \& Anusree, M, Effect of information quality of employment website on attitude toward the website: A moderated mediation study. International Journal of Manpower, 38(5), 2017, pp 729-745.

[50] Radulovic, F., Mihindukulasooriya, N., García-Castro, R., \& Gómez-Pérez, A, A comprehensive quality model for linked data. Semantic Web, 9(1), 2018, pp 3-24.

[51] Rezaei, S., Ali, F., Amin, M., \& Jayashree, S, Online impulse buying of tourism products: the role of web site personality, utilitarian and hedonic web browsing. Journal of Hospitality and Tourism Technology, 7(1), 2016, pp 60-83.

[52] Ringle, C. M., Sarstedt, M., \& Straub, D, A critical look at the use of PLS-SEM in MIS Quarterly. MIS Quarterly (MISQ), 36(1), 2012

[53] Santos-Vijande, M. L., López-Sánchez, J. Á., \& González-Mieres, C, Organizational learning, innovation, and performance in KIBS. Journal of Management \& Organization, 18(6), 2012, pp 870-904.

[54] Shafir, E., Simonson, I., \& Tversky, A, Reason-based choice. Cognition, 49(1-2), 1993, pp 11-36.

[55] Ajai Krishnan G and Dr. M. Nandhini, Consumers Brand Preference and Purchase Intention Towards Gold Jewellery with Special Reference to School Teachers in Kottayam District. International Journal of Civil Engineering and Technology, 8(12), 2017, pp. 278-286.

[56] Shahbazi, M., Farajpahlou, A., Osareh, F., \& Rahimi, A, Development of a scale for data quality assessment in automated library systems. Library \& Information Science Research, 41(1), 2019, pp 78-84. 
[57] Simonson, I., \& Nowlis, S. M, The role of explanations and need for uniqueness in consumer decision making: Unconventional choices based on reasons. Journal of Consumer Research, 27(1), 2000, pp 49-68.

[58] Srinivasan, S., Rutz, O. J., \& Pauwels, K, Paths to and off purchase: quantifying the impact of traditional marketing and online consumer activity. Journal of the Academy of Marketing Science, 44(4), 2016, pp 440-453.

[59] Stone, M, Cross-validatory choice and assessment of statistical predictions. Journal of the Royal Statistical Society: Series B (Methodological), 36(2), 1974, pp 111-133.

[60] Usakli, A., \& Baloglu, S, Brand personality of tourist destinations: An application of self-congruity theory. Tourism Management, 32(1), 2011, pp 114-127.

[61] Vieira, V., Santini, F. O., \& Araujo, C. F, A meta-analytic review of hedonic and utilitarian shopping values. Journal of Consumer Marketing, 35(4), 2018, pp 426-437.

[62] Voss, K. E., Spangenberg, E. R., \& Grohmann, B, Measuring the hedonic and utilitarian dimensions of consumer attitude. Journal of marketing research, 40(3), 2003, pp 310-320.

[63] Wand, Y., \& Wang, R. Y, Anchoring data quality dimensions in ontological foundations. Communications of the ACM, 39(11), 1996, pp 86-95.

[64] Wang, E. S.-T, Creating utilitarian and hedonic value from website quality and online retail performance. Journal of Electronic Commerce in Organizations (JECO), 15(3), 2017, pp 1-13.

[65] Wang, R. Y., \& Strong, D. M, beyond accuracy: What data quality means to data consumers. Journal of management information systems, 12(4), 1996, pp 5-33.

[66] Yamsaengsung, S., \& Papasratorn, B, Towards Improving User Interaction with Navigation Apps: an Information Quality Perspective. KnE Social Sciences, 3(1), 2018, pp 119-131.

[67] Yusuf, A. S., Che Hussin, A. R., \& Busalim, A. H, Influence of e-WOM engagement on consumer purchase intention in social commerce. Journal of Services Marketing, 32(4), 2018, pp 493-504.

[68] Zheltukhina, M. R., Krasavsky, N. A., Slyshkin, G. G., \& Ponomarenko, E. B, Utilitarian and Aesthetic Values in the Modern German Society (Through the Example of Print Media Advertisements). International Electronic Journal of Mathematics Education, 11(5), 2016, pp 1411-1418. 